\title{
Apocynin Prevents Abnormal Megakaryopoiesis and Platelet Activation Induced by Chronic Stress
}

\author{
Leonardo Sandrini, ${ }^{1,2}$ Alessandro Ieraci, ${ }^{2}$ Patrizia Amadio, ${ }^{1}$ Maurizio Popoli, ${ }^{2}$ \\ Elena Tremoli, ${ }^{1}$ and Silvia S. Barbieri ${ }^{1}$ \\ ${ }^{1}$ Centro Cardiologico Monzino, IRCCS, Milan, Italy \\ ${ }^{2}$ Dipartimento di Scienze Farmacologiche e Biomolecolari, Università degli Studi di Milano, Milan, Italy \\ Correspondence should be addressed to Silvia S. Barbieri; silvia.barbieri@ccfm.it
}

Received 3 July 2017; Accepted 24 September 2017; Published 28 November 2017

Academic Editor: Jeannette Vasquez-Vivar

Copyright ( 2017 Leonardo Sandrini et al. This is an open access article distributed under the Creative Commons Attribution License, which permits unrestricted use, distribution, and reproduction in any medium, provided the original work is properly cited.

\begin{abstract}
Environmental chronic stress (ECS) has been identified as a trigger of acute coronary syndromes (ACS). Changes in redox balance, enhanced reactive oxygen species (ROS) production, and platelet hyperreactivity were detected in both ECS and ACS. However, the mechanisms by which ECS predisposes to thrombosis are not fully understood. Here, we investigated the impact of ECS on platelet activation and megakaryopoiesis in mice and the effect of Apocynin in this experimental setting. ECS induced by 4 days of forced swimming stress (FSS) treatment predisposed to arterial thrombosis and increased oxidative stress (e.g., plasma malondialdehyde levels). Interestingly, Apocynin treatment prevented these alterations. In addition, FSS induced abnormal megakaryopoiesis increasing the number and the maturation state of bone marrow megakaryocytes (MKs) and affecting circulating platelets. In particular, a higher number of large and reticulated platelets with marked functional activation were detected after FSS. Apocynin decreased the total MK number and prevented their ability to generate ROS without affecting the percentage of $\mathrm{CD} 42 \mathrm{~d}^{+}$cells, and it reduced the platelet hyperactivation in stressed mice. In conclusion, Apocynin restores the physiological megakaryopoiesis and platelet behavior, preventing the detrimental effect of chronic stress on thrombosis, suggesting its potential use in the occurrence of thrombosis associated with ECS.
\end{abstract}

\section{Introduction}

Thrombosis is a pathological event, which can affect both veins and arteries, whose clinical manifestation is associated with deep vein thrombosis, myocardial infarction, cerebral stroke, and pulmonary embolism. A number of studies have shown a strong link between cardiovascular disease and psychological stress. Thus, psychological stress has been recently included as risk factor for cardiovascular disease [1-3]. In particular, psychological/environmental stress, inducing hyperactivation of platelets and coagulation factors and modifying the normal fibrinolytic processes, triggers a hypercoagulable state [4], predisposing to cardiovascular disease.

Interestingly, modifications in the redox balance and in the reactive oxygen species (ROS) production and alterations of genes regulating antioxidant systems, including
NADPH oxidase, occur in both chronic stress and cardiovascular disease [5-9].

Several studies showed that endothelial cells, leukocytes, vascular smooth muscle cells, fibroblasts, and platelets are important sources of ROS after vascular injury and that these ROS can regulate platelet activation $[10,11]$, triggering a vicious circle that leads to thrombosis. However, the mechanisms by which chronic environmental stress predisposes to thrombosis and thereby to cardiovascular disease are not fully understood.

Therapeutic approaches targeting ROS production to reduce atherothrombotic risk and to prevent neurodegenerative diseases are developing [12-14]. One of the most promising antioxidant drugs in experimental models is Apocynin (4-hydroxy-3-methoxyacetophenone) [15]. Apocynin is an active principle with anti-inflammatory properties [16] isolated from the root of the medicinal plant Picrorhiza Kurroa 


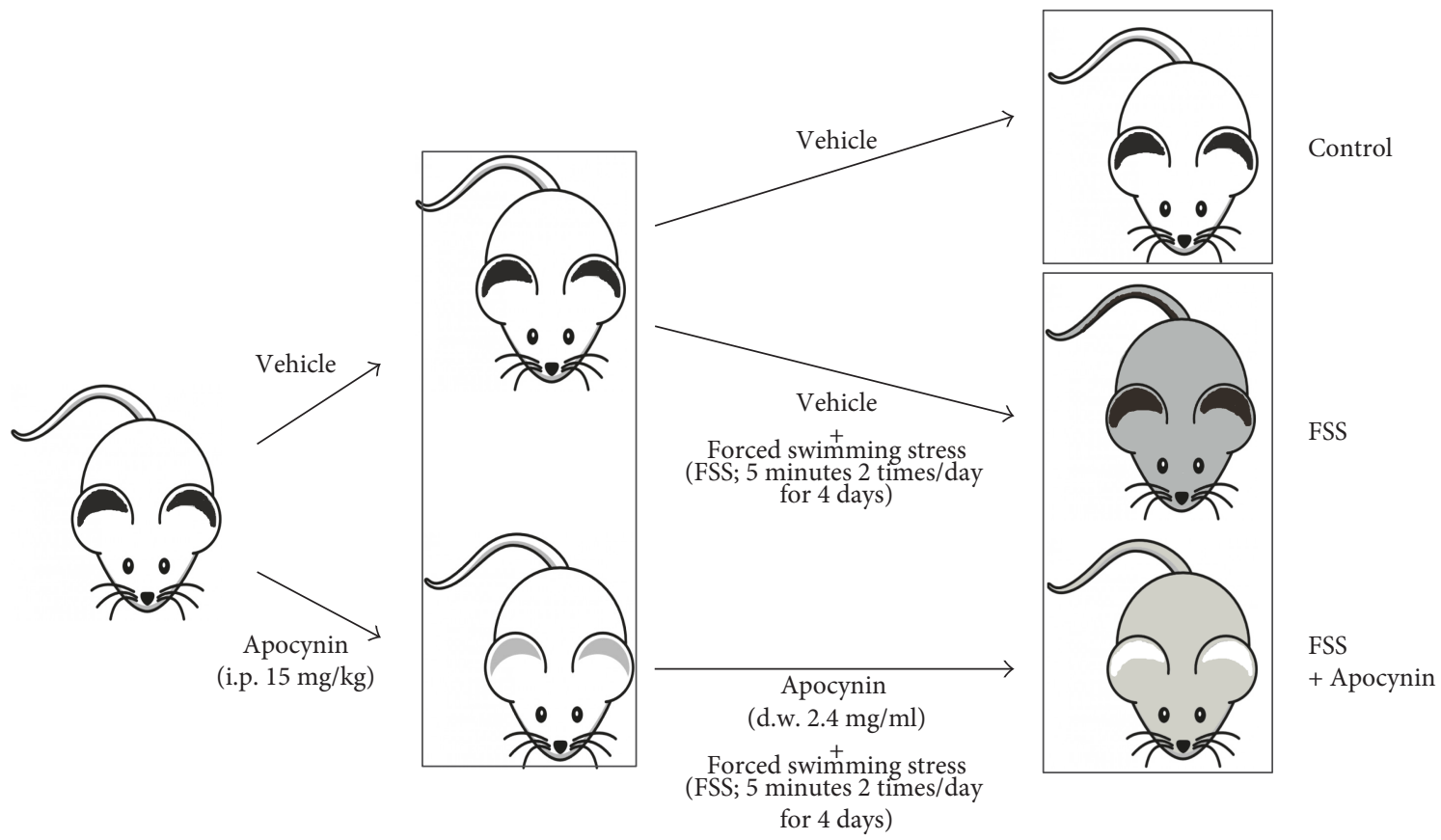

FIGURE 1: Design of the experiment: mice were randomized in 3 groups: control (vehicle), FSS (vehicle treatment and exposure to forced swim stress for 5 minutes two times/day as indicated), and FSS plus Apocynin (Apocynin treatment and exposure to forced swim stress for 5 minutes two times/day as indicated) and then sacrificed as indicated in the Methods 18 hours after the last section of stress.

(Scrophulariaceae) [17]. Apocynin affects ROS generation inhibiting NADPH oxidase enzyme activation, and it turns out to be a scavenger of hydrogen peroxide $[15,18]$.

In this study, we aimed at evaluating the beneficial effect(s), if any, of Apocynin in preventing thrombosis induced by chronic psychological/behavioral stress and at exploring the underlying mechanism(s).

\section{Methods}

2.1. Ethics Statement and Experimental Design. The experimental groups consisted of FVB male mice (12-14 weeks old) supplied by Charles River and housed in a temperature-controlled, $12 \mathrm{~h}$ light/dark cycle environment with ad libitum access to water and fed on standard pellet diet. All experiments were approved by the National Ministry of Health-University of Milan Committee and of DGSA. Surgical procedures were performed in mice anesthetized with ketamine chlorhydrate $(75 \mathrm{mg} / \mathrm{kg}$; Intervet) and medetomidine $(1 \mathrm{mg} / \mathrm{kg}$; Virbac). Mice were randomized in different groups. Apocynin (Sigma-Aldrich; $15 \mathrm{mg} / \mathrm{kg}$ ) or dimethylsulfoxide (DMSO) was intraperitoneally (i.p.) injected $1 \mathrm{~h}$ before start the first session of stress [8] and then added to the drinking water $(300 \mathrm{mg} / \mathrm{kg})$ for 5 days [19], corresponding to $2.4 \mathrm{mg} / \mathrm{ml}$ since our mice approximately drink 3$3.5 \mathrm{ml}$ water/day. No side effects were reported during long time treatment (2-16 weeks) with Apocynin [19, 20]. The chronic forced swim stress (FSS) was performed as previously described [8]. Briefly, mice were individually placed in a $2000 \mathrm{ml}$ glass beaker (height, $24 \mathrm{~cm}$; diameter, $12 \mathrm{~cm}$ ) filled with $1500 \mathrm{ml}$ of room temperature water for $5 \mathrm{~min}$ twice a day for 4 consecutive days. Mice were then quickly dried with a towel and returned to their home cage. This model of stress is based on the well-established finding that repeated exposure to an inescapable stress, for which no active coping responses are available, induces depressive- and anxious-like behaviors in mice [21-23]. Interestingly, this model of stress is considered a chronic model because behavioral alterations are chronically maintained for more than 4 weeks [24-26]. Experiments were performed, and tissue, were collected $18 \mathrm{~h}$ after the last section of FSS (Figure 1).

Blood was collected into $3.8 \%$ sodium citrate (1:10 vol:vol) from anesthetized mice at time indicated. For plasma preparation, citrated blood was centrifuged at $3000 \mathrm{rpm}$ for $20 \mathrm{~min}$ at $4^{\circ} \mathrm{C}$ to obtain plasma, which was immediately stored at $-80^{\circ} \mathrm{C}$ until further analysis.

2.2. Whole Blood Counts. Blood was collected into sodium citrate from anesthetized mice by cardiac venipuncture, and the differential white blood cell and platelet count were performed on a Beckman Coulter AU480.

2.3. Rotational Thromboelastometry. Rotational Thromboelastography $\left(\right.$ ROTEM $\left.^{\circledR}\right)$ was used to measure coagulability in whole blood as previously described [27]. Briefly, citrated whole blood was added to a cuvette containing star-tem ${ }^{\circledR}$ solution or fib-tem ${ }^{\circledR}$ solution, and recording was started immediately and was allowed to proceed for $60 \mathrm{~min}$ according to the manufacturer's instructions. Clotting characteristics were analysed in terms of clotting time (CT, time necessary for the formation of a clot with a diameter of $2 \mathrm{~mm}$ ) and clot formation time (CFT, kinetic of a stable clot formation by activated platelets and fibrin) and maximum 
clot firmness and maximum clot elasticity (MCF and MCE, measure of the consistence and elasticity of the clot, resp.) were collected.

2.4. Malondialdhyde and NADPH/NADP Analyses. Malondialdhyde (Cat. MBS269473) and NADPH/NADP (Cat. MBS169276) were measured in plasma and bone marrow, respectively, by ELISA kit (MyBioSource) according the to manufacturer's instructions.

2.5. Arterial Thrombosis Model. Experimental arterial thrombosis was induced as previously described [28]. The left carotid artery of anesthetized mice was dissected free and placed in the probe (model $0.7 \mathrm{~V}$, Transonic System) connected to transonic flow meter (Transonic T106). After blood flow stabilization (baseline flow constant for $7 \mathrm{~min}$ at least $0.8 \mathrm{ml} / \mathrm{sec}$ ), a $1 \times 1 \mathrm{~mm}$ strip of filter paper (Whatman $\mathrm{N}^{\circ} 1$ ) soaked with $\mathrm{FeCl}_{3}$ (10\% solution; Sigma-Aldrich) was applied over the carotid artery. After $3 \mathrm{~min}$, the filter paper was removed, the carotid artery was washed with PBS, and the flow was recorded for $30 \mathrm{~min}$. An occlusion was considered to be total and stable when the flow was reduced by $>90 \%$ from baseline until the 30-minute observation time, with the flow during this period not changing by more than $1 \%$ from baseline per second.

2.6. Platelet-Leukocyte Aggregate Analysis. Platelet/monocyte and platelet/neutrophil aggregates were analysed as previously described [29]. Briefly, citrated blood was stimulated where indicated with ADP for 5 minutes and red blood cells were lysed by FACS Lysing solution (BD Biosciences); samples were stained with the anti-CD45, anti-CD41, and anti-CD14 or anti-Lys6G (eBiolegend, Cat. 103101, 133901, 150101, and 127601, resp.) and analysed by flow FACS "Novocyte 3000." A minimum of 5000 events was collected in the $\mathrm{CD}_{14}{ }^{+}$or $\mathrm{Lys}_{6 \mathrm{G}}^{+}$gate.

2.7. Platelet Studies. Washed platelets (WPs) were obtained from platelet-rich plasma (PRP), isolated following centrifugation at $100 \mathrm{~g}$ for $10 \mathrm{~min}$ of citrated blood as previously described [30], with serial centrifugation and addition of $0.2 \mathrm{mM} \mathrm{PGI}$ and $0.01 \mathrm{mg} / \mathrm{l}$ apyrase. Platelet pellets were resuspended in HEPES-Tyrode's buffer $(137 \mathrm{mM} \mathrm{NaCl}$, $20 \mathrm{mM}$ HEPES, $5.6 \mathrm{mM}$ glucose, $0.35 \%$ bovine serum, $1 \mathrm{mM} \mathrm{MgCl}, 2.7 \mathrm{mM} \mathrm{KCl}$, and $3.3 \mathrm{mM} \mathrm{NaH}_{2} \mathrm{PO}_{4}$ ).

$25 \mu \mathrm{l}$ of WPs $\left(5 \times 10^{4} / \mu \mathrm{l}\right.$ in HEPES-Tyrode's buffer supplemented with $1 \mathrm{mM} \mathrm{CaCl}$ ) was mixed with a saturating concentration of PE-conjugated JON/A (Emfret Analytic, Cat. M023-2) antibody, raised against the activated form of GPIIbIIIa $(\alpha \mathrm{II} \beta I I \mathrm{I}$ integrin), or with anti-CD62P and FITC-conjugated antibody (P-selectin; BD Biosciences, Cat. 553744), and the mixture reacted with different concentrations of ADP or thrombin for 15 minutes at room temperature. The reaction was stopped by $400 \mu \mathrm{l}$ ice-cold PBS, and samples were analysed within 30 minutes. Platelets were identified by forward and side scatter distribution and by anti-CD41 positivity.

Reticulated platelets (RP) were identified by the thiazole orange method [30]: $10 \mu \mathrm{l}$ of PRP was incubated with $390 \mu \mathrm{l}$ of thiazole orange (Retic-Count; BD Biosciences) or
PBS as control and anti-CD41 at room temperature for 10 minutes, in the dark.

Immediately after incubation, samples were analysed by flow cytometry collecting 10000 CD41-positive events; the percentage of RP was recorded, and the absolute number of $\mathrm{RP}$ was calculated by multiplying by the platelet count.

2.8. Megakaryocyte Analyses. For single-cell suspensions from bone marrow, BM was flushed in PBS $\left(\mathrm{Ca}^{2+}\right.$ - and $\mathrm{Mg}^{2+}$ free) containing $3 \%$ BSA, $5.5 \mathrm{mM}$ D-glucose, $10.2 \mathrm{mM}$ trisodium citrate, and $10 \mu \mathrm{M} \mathrm{PGE}_{1}$ were filtered through a sterile nylon mesh $(70 \mu \mathrm{m})$ and centrifuged ( $5 \mathrm{~min}, 200 \mathrm{~g}$ ). Cells were first resuspended in FACS Lysing solution to lyse red blood cells, then washed and resuspended in PBS plus 2\% FBS, and stained for 20 minutes on ice with PE-conjugated CD41 (BD Biosciences, Cat. 558040) and FITC-conjugated CD61 (BD Biosciences, Cat. 561911) or FITC-conjugated CD42d (Emfret Analytics, Cat. M061-1). The percentage of CD41-positive $\left(\mathrm{CD} 41^{+}\right)$and CD61-positive $\left(\mathrm{CD} 61^{+}\right)$cells or of CD41-positive $\left(\mathrm{CD} 41^{+}\right)$ and CD42d-positive $\left(\mathrm{CD} 42 \mathrm{~d}^{+}\right)$cells was evaluated by FACS on a FITC gate, and PE was set at $1 \%$ on samples stained with the control antibody [30]. $\mathrm{CD} 41^{+} / \mathrm{CD} 61^{+}$was used as marker of total megakaryocyte, and $\mathrm{CD} 41^{+} / \mathrm{CD} 42 \mathrm{~d}^{+}$as marker of mature megakaryocytes.

For ROS detection, single-cell suspensions from bone marrow were stained with PE-conjugated CD41 and incubated with $20 \mu \mathrm{M} \mathrm{H} \mathrm{H}_{2} \mathrm{DCF}-\mathrm{DA}\left(2^{\prime}, 7^{\prime}\right.$-dichlorodihydrofluorescein diacetate, Sigma-Aldrich) for 15 minutes at $37^{\circ} \mathrm{C}$ and $5 \% \mathrm{CO}_{2}$, then samples were analysed by FACS. Live events were collected on the basis of side scatter plots. MKs were gated by identification of CD41-PE-positive cells [31].

Flow cytometry was performed on a flow FACS "Novocyte 3000," collecting 3000 events per sample.

2.9. Bone Marrow Histology. Immunohistochemistry was performed on BM as previously described [30]. Tissues were fixed overnight in $4 \%$ formalin, embedded in paraffin, cut at $3 \mu \mathrm{m}$, and mounted on polarized slides. BM samples were decalcified in 10\% EDTA, pH 8 for 10 days before paraffin embedding. Sections were stained in Hematoxylin and Eosin (H\&E). Slides were dewaxed, rehydrated, washed in PBS containing $0.1 \%$ Triton X100 for 15 minutes, and treated with $3 \% \mathrm{H}_{2} \mathrm{O}_{2}$ for 10 minutes to block endogenous peroxidase. Antigen retrieval was performed with $0.01 \mathrm{M}$ citrate buffer (pH6) in a water bath at $98^{\circ} \mathrm{C}$ for 10 or 30 minutes according to the antibody used. Slides were incubated overnight at $4^{\circ} \mathrm{C}$ with the following primary antibodies: anti-NOX1 polyclonal antibody $(1: 200$, GeneTex, Cat. GTX103888) or with rabbit preimmune IgGs (Vector Laboratories, Cat. I-1000) as negative controls. For immunoperoxidase, biotinylated anti-rabbit secondary antibody (Dako, Glostrup, Denmark, Cat. E0432) and then streptavidin/HRP (Dako, Glostrup, Denmark, Cat. P0397) were used and developed with the DAB substrate kit (Sigma-Aldrich). Slides were lightly counterstained with hematoxylin and observed and digitalized by a Zeiss Axioskop (Carl Zeiss) equipped with an intensified charge-coupled device (CCD) camera system (Photometrics). The number and area of 


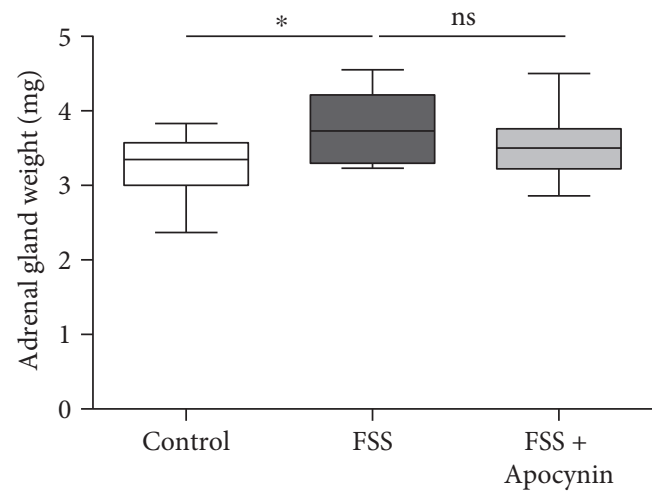

(a)

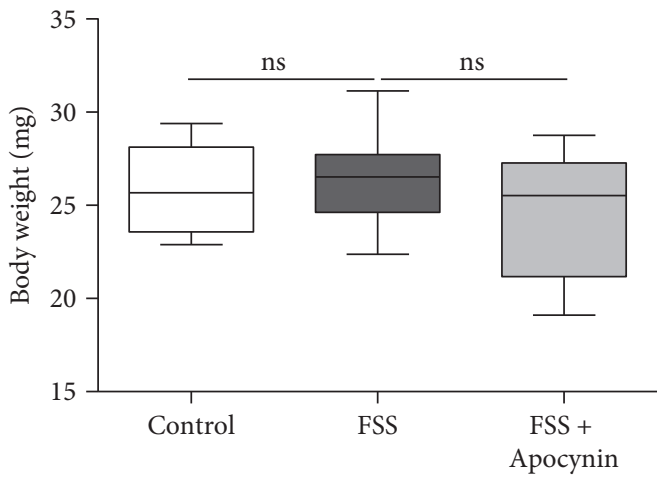

(c)

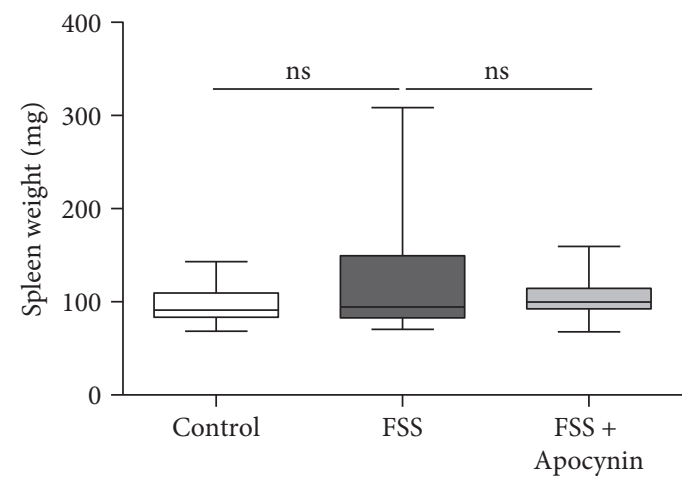

(b)

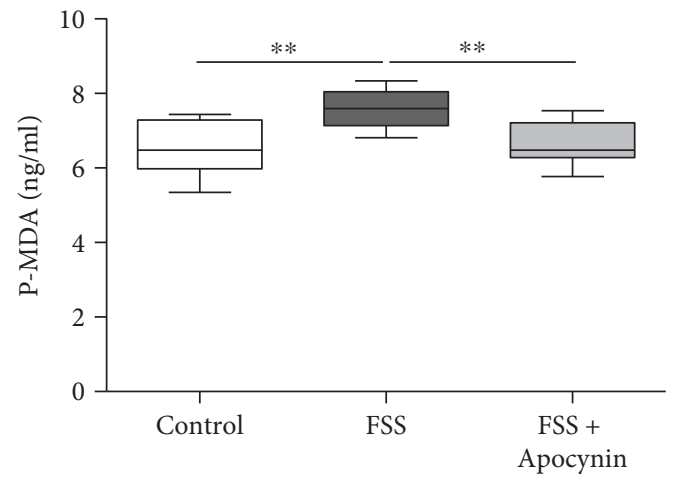

(d)

Figure 2: Forced swimming treatment for 4 days was sufficient to increase oxidative stress. Weight of (a) adrenal gland, (b) spleen, and (c) body and (d) plasma malondialdehyde (P-MDA) levels, from control mice (treated with vehicle) and from mice exposed to forced swimming stress with vehicle (FSS) or with Apocynin (FSS + Apocynin). $n=12$ mice/group. ${ }^{*} p<0.05,{ }^{*} p<0.01$, and ns: nonsignificant. For each box-plot, the center line illustrates the median and box limits indicate the 25th and 75th percentiles. Data were analyzed by the Kruskal-Willis test followed by a Dunn's multiple comparison test.

megakaryocytes were evaluated in hematoxylin and eosin stained sections by counting 5-7 40x microscopic fields for each tissue sample [32].

2.10. Statistical Analysis. Statistical analyses were performed with GraphPad Prism 6.0 and SAS versus 9.4 software (SASA Institute). Data were analyzed by oneor 2-way ANOVA with repeated measures for main effects of treatment and time or stimuli, followed by a Dunn's test or a Bonferroni post hoc analysis as appropriate. Values of $p<0.05$ were considered statistically significant. Data are expressed as mean \pm SEM. For each box-plot, the center line illustrates the median, and box limits indicate the 25th and 75th percentiles.

\section{Results}

3.1. Effect of Apocynin on Chronic Stress and Oxidative Stress. To assess whether the chronic forced swimming treatment for 4 days was sufficient to induce a stress-response, we weighted adrenal glands as an index of terminal phase of hypothalamic-pituitary-adrenal neuroendocrine system activation. As expected, adrenal gland weight was greater in the stressed group of mice compared to the control group $(p<0.05$; Figure 2(a)). Apocynin treatment did not modify the adrenal gland hypertrophy induced by forced swimming stress (FSS; Figure 2(a)), suggesting that Apocynin does not change the physiological response to the stress protocol. No significant difference in spleen or body weight between control and stressed mice with or without Apocynin treatment was found (Figures 2(b) and 2(c)).

Next, we measured the plasma malondialdehyde (P-MDA) levels, as marker of oxidative stress. The P-MDA levels were higher in the FSS-group compared to the control ( $p<0.01$; Figure 2(d)). Interestingly, Apocynin administration restored the normal P-MDA levels in stressed mice (Figure 2(d)).

3.2. Apocynin Prevented Arterial Thrombosis Induced by Forced Swimming Stress (FSS). FSS accelerated occlusion rates in $\mathrm{FeCl}_{3}$-injuried carotid arteries (Figure 3). In particular, $\mathrm{FeCl}_{3}$ application reduced dramatically the blood flow within 10 minutes and led to a stable occlusion in $100 \%$ of mice exposed to FSS, but it was unable to induce a stable occlusion in control mice within the same 30-minute observation period (Figure 3). In mice treated with Apocynin, blood flow was slightly but significantly reduced in the first 10 minutes after topical application of $\mathrm{FeCl}_{3}$ and remained constant over all the observation period (Figure 3 ). The total 


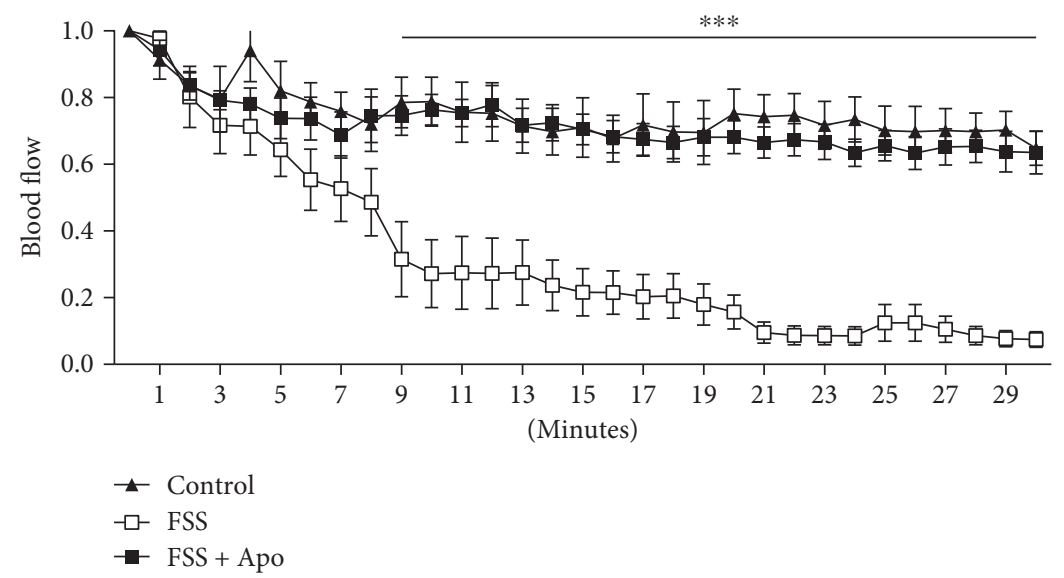

(a)

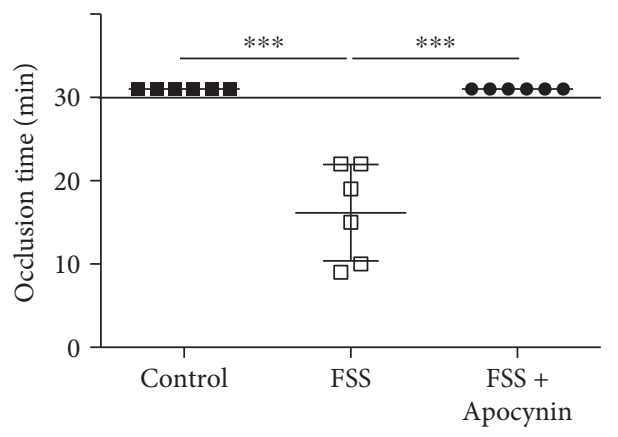

(b)

Figure 3: The propensity to arterial thrombosis induced by chronic stress is prevented by Apocynin treatment. (a) Blood flow in the carotid arteries of control mice (treated with vehicle) and from mice exposed to forced swimming stress with vehicle (FSS) or with Apocynin (FSS + Apocynin) expressed relative to the value before injury. Data shown are mean \pm SEM and analyzed by 2 -way ANOVA with repeated measures for main effects of treatment and time, followed by a Bonferroni post hoc analysis. (b) Time to thrombotic occlusion mice; horizontal bars indicate the mean value for each group. $n=6$ mice/group. ${ }^{* * *} p<0.005$. Data were analyzed by the Kruskal-Willis test followed by a Dunn's multiple comparison test.

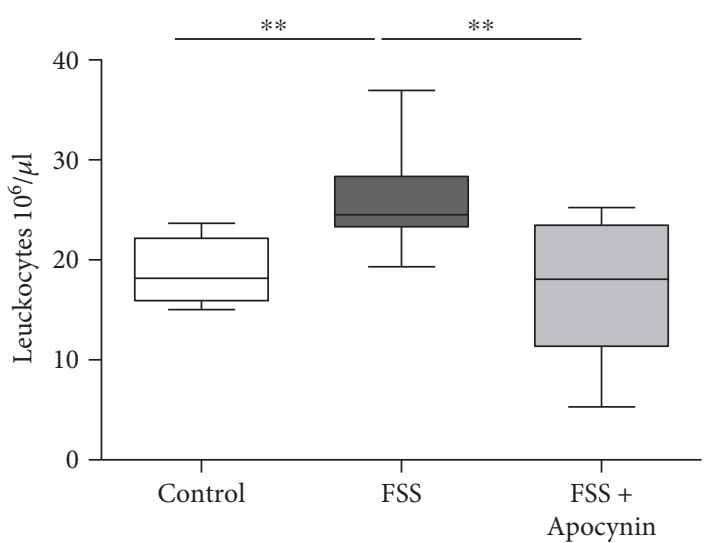

(a)

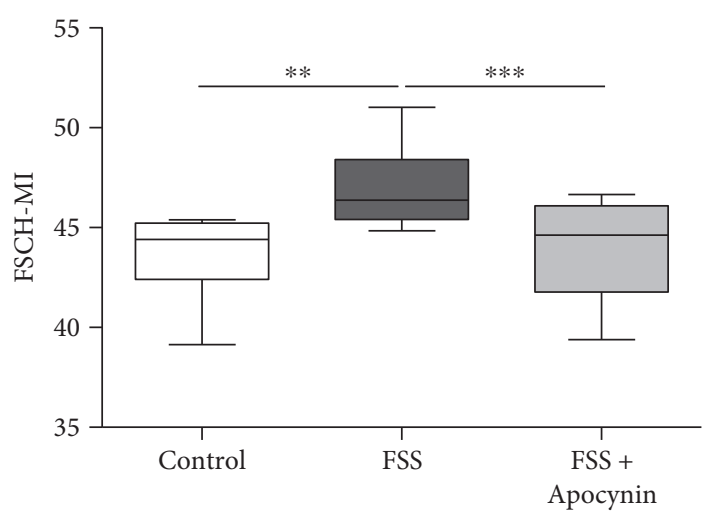

(c)

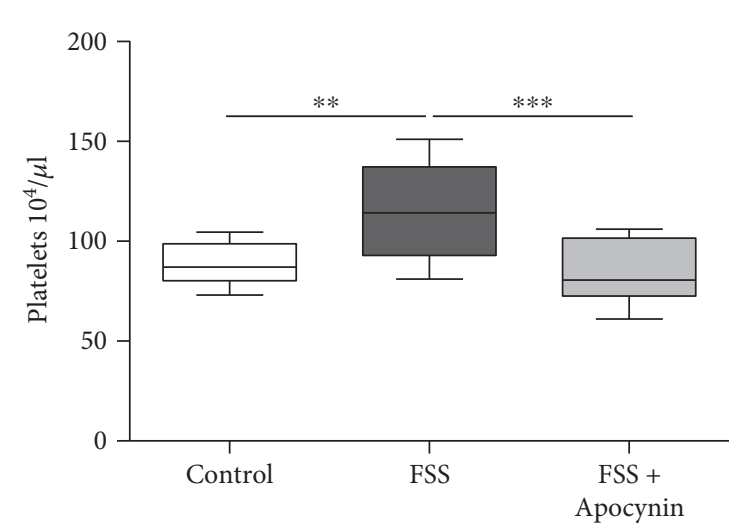

(b)

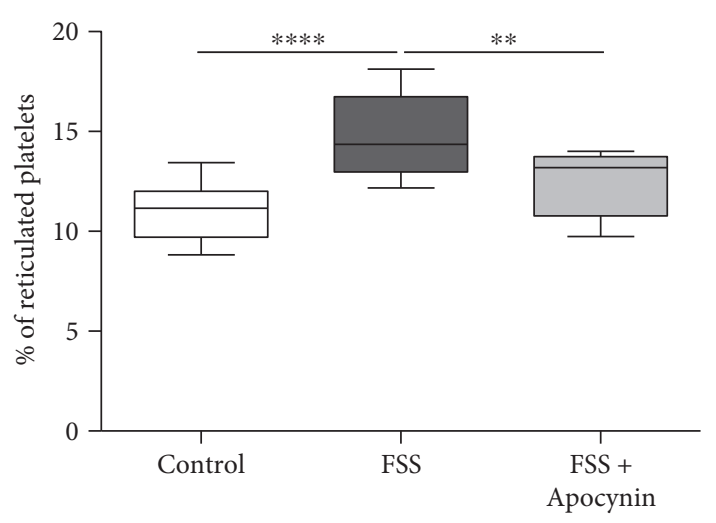

(d)

Figure 4: Modifications of circulating cells induced by chronic stressed are reduced by Apocynin treatment. Numbers of circulating (a) leukocytes and (b) platelets were counted, and (c) platelet size and (d) percentage of reticulated platelets were analysed by flow cytometry in control mice exposed to forced swimming stress (FSS) and treatment with or without Apocynin (FSS + Apocynin). $n=10$ mice/group. ${ }^{* *} p<0.01,{ }^{* * *} p<0.005$, and ${ }^{* * * *} p>0.001$. For each box-plot, the center line illustrates the median and box limits indicate the 25 th and 75 th percentiles. Data were analyzed by the Kruskal-Willis test followed by a Dunn's multiple comparison test. 


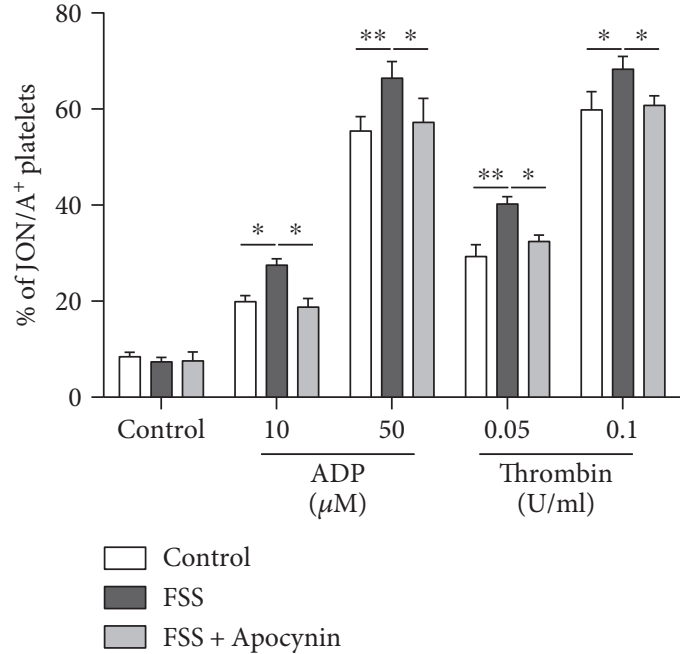

(a)

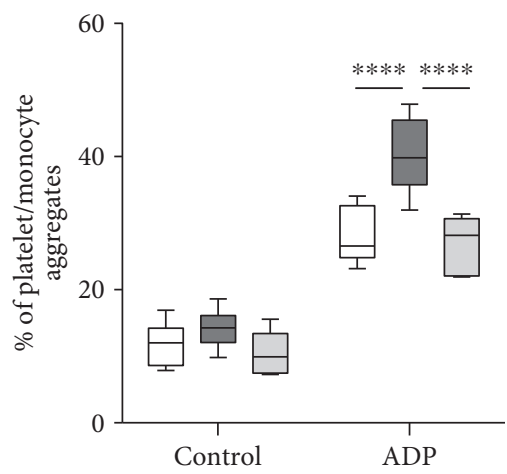

(c)

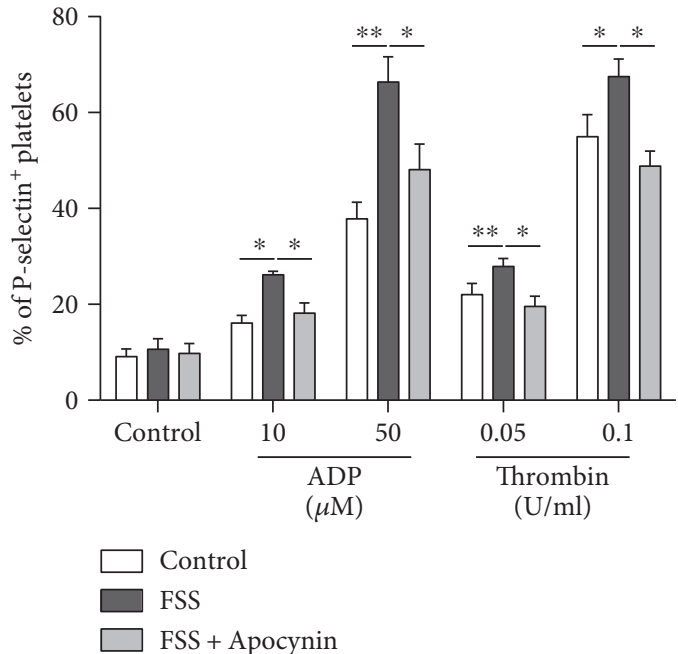

(b)

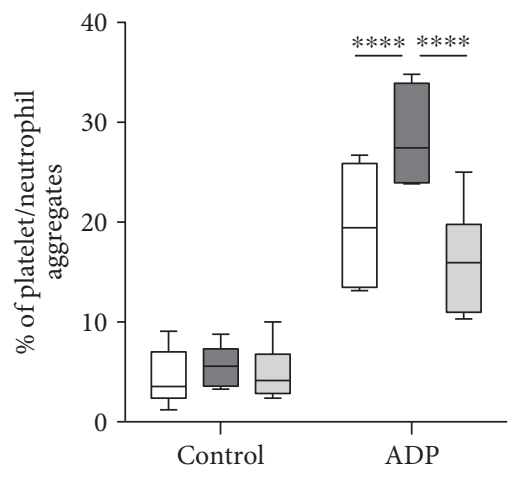

(d)

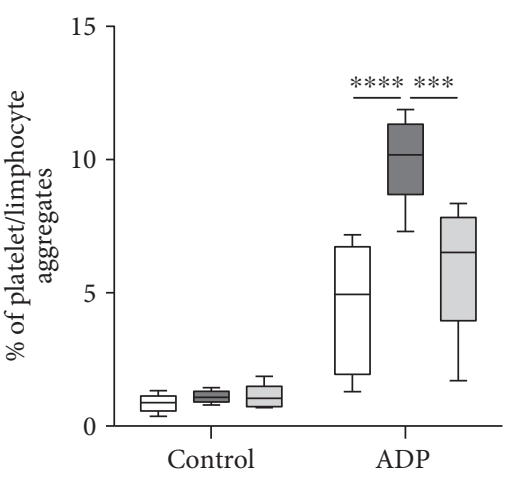

(e)

FIGURE 5: Apocynin decreases platelet activation induced by chronic stress. Flow cytometry analyses of (a) GPIIbIIIa activation (JON/A-PE antibody) and (b) P-selectin expression in washed platelets, and percentage of (c) platelet/monocyte, (d) platelet/neuthrophil, and (e) platelet/ lymphocyte aggregates in whole blood of control mice (treated with vehicle) and of mice exposed to forced swimming stress with vehicle (FSS) or with Apocynin (FSS + Apocynin). $n=6$ mice/group. ${ }^{*} p<0.05,{ }^{* *} p<0.01,{ }^{* * *} p<0.005$, and ${ }^{* * * *} p<0.001$. For each box-plot, the center line illustrates the median and box limits indicate the 25 th and 75 th percentiles. Data were analyzed by 2 -way ANOVA with repeated measures for main effects of treatment and stimuli, followed by a Bonferroni post hoc analysis.

occlusion of carotid artery induced by FSS was completely prevented in all treated mice (Figure 3 ).

No significant difference in terms of basal levels of blood flow was noted between the animal groups (control: $0.616 \pm 0.07 \mathrm{ml} / \mathrm{min} ;$ FSS: $0.557 \pm 0.10 \mathrm{ml} / \mathrm{min}$ and FSS + Apocynin: $0.543 \pm 0.08 \mathrm{ml} / \mathrm{min}$ ).

3.3. Effect of Forced Swimming Stress (FSS) on Blood Hemostasis. Thromboelastography analysis (ROTEM analyses) in whole blood provided evidence that FSS affected blood hemostasis by shortening the clotting formation time (CFT: control: $160.2 \pm 10.39 \mathrm{sec}$ and FSS: $90.67 \pm 9.90 \mathrm{sec}$, $p<0.005)$ and increasing the maximum clot firmness (MCF: control: $60.33 \pm 1.76 \mathrm{~mm}$ and FSS: $67.83 \pm 1.6 \mathrm{~mm}$, $p<0.05$ ) and maximum clot elasticity (MCE: control: $154.5 \pm 11.73 \mathrm{~mm}$ and FSS: $214.8 \pm 16.27 \mathrm{~mm}, p<0.05)$. In contrast, similar coagulation time in na-tem test (CT: control: $293.7 \pm 15.38 \mathrm{sec}$ and FSS: $235.3 \pm 25.19 \mathrm{sec}, p=0.087)$ and comparable MCF in fib-tem test (MCF: control:
$20.67 \pm 1.91 \mathrm{~mm}$ and FSS: $23.50 \pm 2.62 \mathrm{~mm}, p=0.617)$ were detected in control and FSS groups.

These data suggest that chronic stress did not affect coagulation pathway and fibrinogen but instead, it promoted hyperactivation of platelets.

3.4. Effect of Apocynin on Circulating Cell Number and Platelet Function in Response to Forced Swimming Stress (FSS). As previously shown in mouse and human studies [33-35], FSS increased the number of circulating leukocytes (Figure $4(\mathrm{a}), p<0.01$ ) and platelets (Figure $4(\mathrm{~b}), p<0.01$ ) and enhanced platelet size (Figure $4(\mathrm{c}), p<0.01$ ) and the percentage of reticulated platelets (Figure $4(\mathrm{~d}), p<0.001$ ). Apocynin reverted these changes in stressed mice toward the restoration of the physiological number of leukocyte and platelet shape (Figure 4).

Interestingly, activation of integrin $\alpha \operatorname{IIb} \beta 3$ (GPIIbIIIa) (Figure $5(\mathrm{a}), p<0.05$ ) as well as the expression of P-selectin on platelet surface (Figure $5(\mathrm{~b}), p<0.05$ ) in response to 

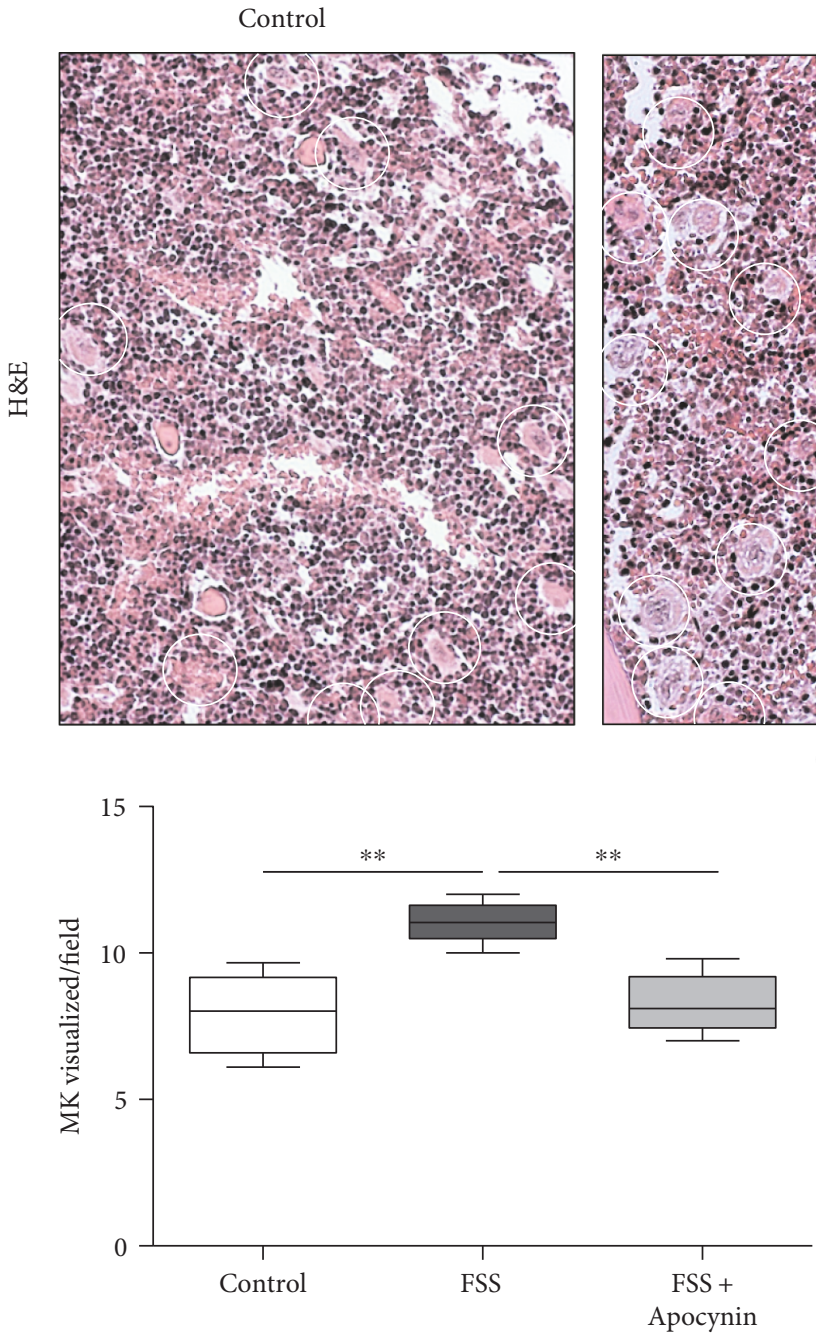

(b)

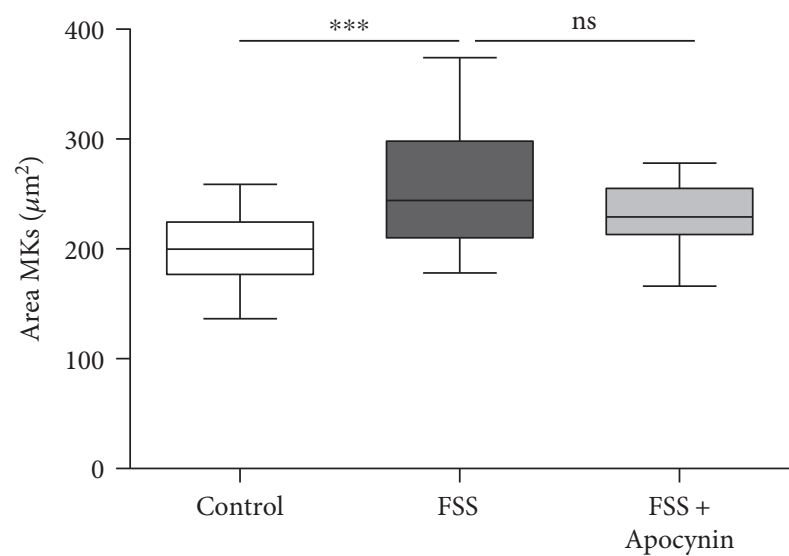

(d)
FSS

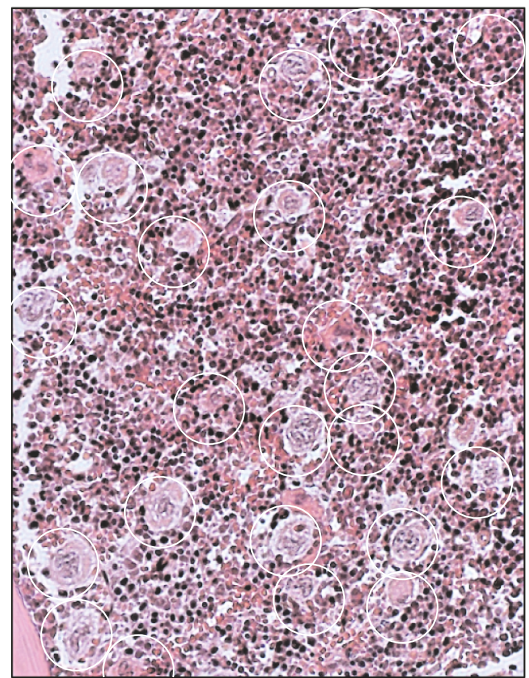

(a)
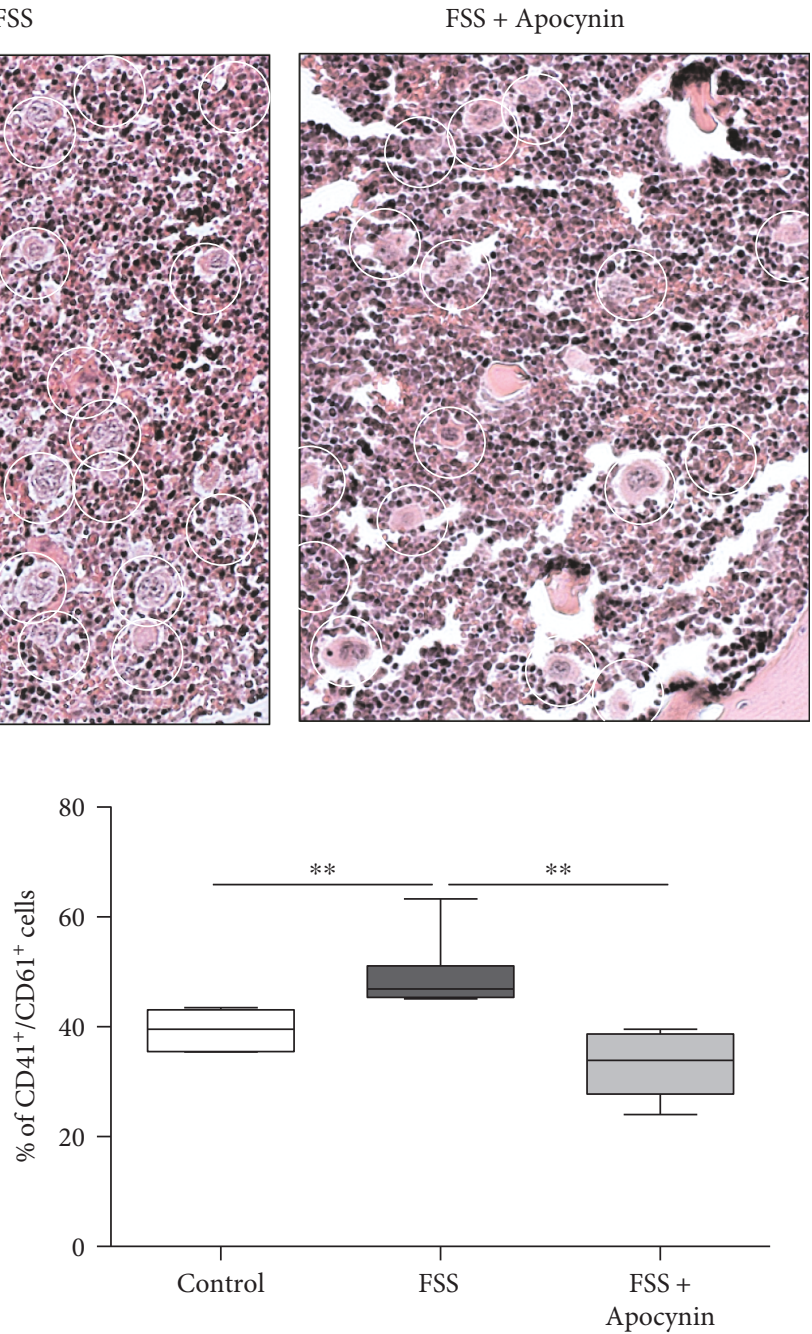

(c)

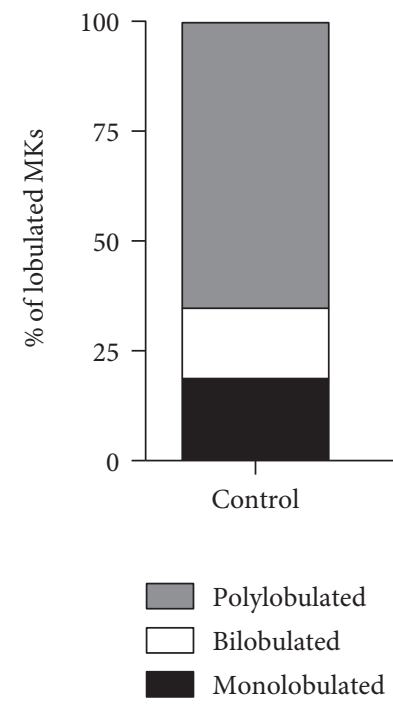

FIgURe 6: Continued. 


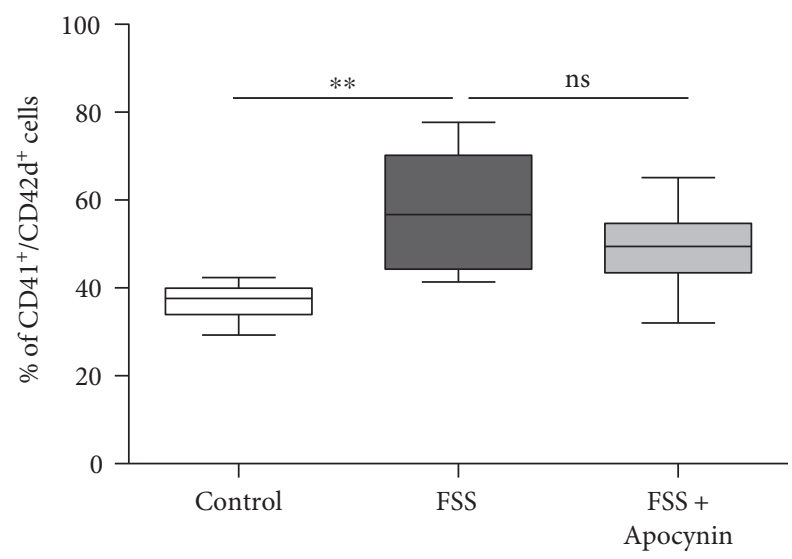

(f)

Figure 6: Apocynin partially reduces megakaryocyte alteration induced by chronic stress. (a) Hematoxylin and Eosine (H\&E) staining of bone marrow from control mice (treated with vehicle) and from mice exposed to forced swimming stress with vehicle (FSS) or with Apocynin (FSS + Apocynin). Circle indicates MKs. (b) Quantification of panel (a) expressed as megakaryocytes per filed (40x magnification). Flow cytometric analyses: (c) percentage of $\mathrm{CD} 41^{+} / \mathrm{CD} 61^{+}$cells and (f) percentage of $\mathrm{CD} 41^{+} / \mathrm{CD} 42 \mathrm{~d}^{+}$cells in bone marrow of mice. Analysis of (d) area and of (e) nuclear complexity in megakaryocytes from control, stress, and stress + Apocynin mice. $n=6$ mice/group. ${ }^{* *} p<0.01,{ }^{* * *} p<0.005$, and $n s=$ nonsignificant. For each box-plot, the center line illustrates the median and box limits indicate the 25 th and 75 th percentiles. Data were analyzed by the Kruskal-Willis test followed by a Dunn's multiple comparison test.

different stimulus was higher in stressed mice compared to control. The greater expression of P-selectin went hand in hand with the enhanced percentage of platelet monocyte (Figure 5(c), $p<0.001$ ), platelet/neutrophil (Figure 5(d), $p<0.001$ ), or platelet/lymphocyte (Figure 5(e), $p<0.001$ ) aggregates in response to ADP.

Remarkably, the platelet hyperreactivity induced by FSS was completely prevented by Apocynin treatment (Figure 5).

3.5. Effect of Apocynin on Megakaryopoiesis in Stressed Mice. To assess whether the thrombocytosis consequent to FSS exposure was associated to the abnormal megakaryopoiesis, bone marrow megakaryocytes were analyzed.

Histopathological analysis of bone marrow section (Figure 6(a)) revealed a higher number of megakaryocytes (MKs) in stressed mice compared to control (FSS: $11.04 \pm$ $0.28 \mathrm{MKs} /$ field versus control: $7.93 \pm 0.58 \mathrm{MKs} /$ field, $p<$ 0.01 ; Figure $6(\mathrm{~b})$ ), and flow cytometer analyses showed that FSS increased significantly the percentage of $\mathrm{CD} 41^{+} / \mathrm{CD} 61^{+}$ cells in bone marrow (Figure 6(c), $p<0.01$ ). In addition, careful analyses of these sections revealed that megakaryocytes from stressed mice were larger (Figure 6(d), $p<0.005$ ) and displayed greater nuclear complexity (Figure 6(e)) compared to control. In particular, higher percentage of polylobulated megakaryocytes $(p<0.001)$ and lower percentage of mononucleated $(p<0.01)$ or binucleated $(p<0.05)$ megakaryocytes were detected in bone marrow from stressed mice. The advanced maturation state of megakaryocytes from stressed mice suggested by morphological examination was sustained by the enhanced expression of lineage differentiation marker CD42d (Figure 6(f), $p<0.01$ ). Interestingly, Apocynin decreased markedly the number of megakaryocytes $(p<0.01)$, but only slightly reduced the total area, without affecting their maturation state.

Finally, we showed that FSS decreased the NADPH/ $\mathrm{NADP}^{+}$ratio (Figure $7(\mathrm{a})$ ) and upregulated NOX1 expression in bone marrow, including megakaryocytes (Figure 7(b)). Interestingly, NOX1 is the most abundant NOX isoform in this type of cells [36]. In addition, FSS specifically induced reactive oxygen species (ROS) production in megakaryocytes (Figure $7(\mathrm{c}), p<0.01$ ). As expected, Apocynin restored the physiological $\mathrm{NADPH} / \mathrm{NADP}^{+}$ratio and markedly decreased ROS generation and NOX1 expression induced by FSS (Figure 7).

\section{Discussion}

In this study, we show that Apocynin treatment, by preventing ROS generation, restores the physiological megakaryopoiesis and platelet function and reduces arterial thrombosis. Overall, these findings suggest that ROS play a key role in the susceptibility to thrombosis induced by chronic psychological/behavioral stress, affecting the production/activation of megakaryocytes, with consequent increase of both number and reactivity of circulating platelets.

Chronic environmental/psychological stress increases the hypothalamic-pituitary-adrenal axis activation [37] and induces a dysregulation in norepinephrine system that turns a homeostatic stress response into a pathological stress response [38]. Then, the observation that chronic environmental stress accelerates norepinephrine-mediated hematopoiesis promoting atherosclerotic plaque features associated with vulnerable lesions [35] well explained the correlation between psychological stress and acute myocardial infarction emerged from the INTERHEART study [39]. However, chronic environmental stress increases the risk for cardiovascular disease also promoting a prothrombotic state [40-42]. As a matter of fact, chronic stress increases the levels of tissue factor and of the plasminogen activation inhibitor-1 [40-42] and the number of circulating platelets [33]. Interestingly, here, we showed that 5 minutes of "forced swimming stress" 


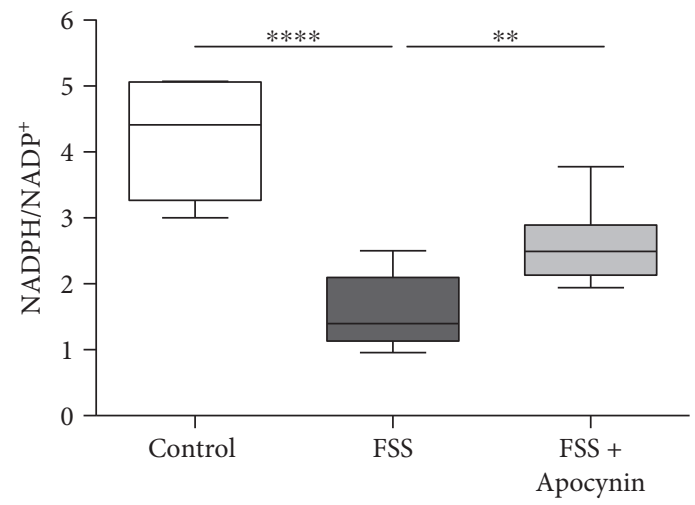

(a)

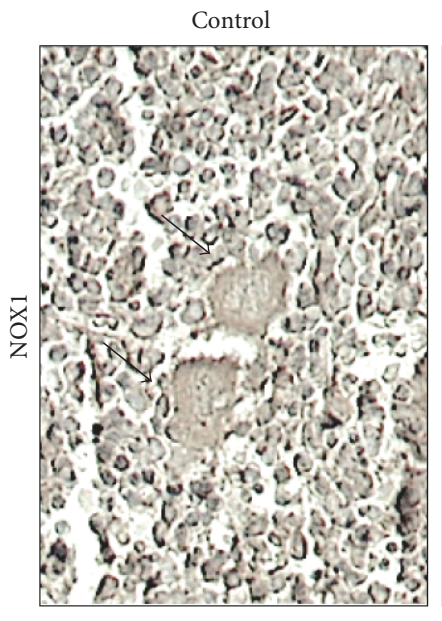

FSS

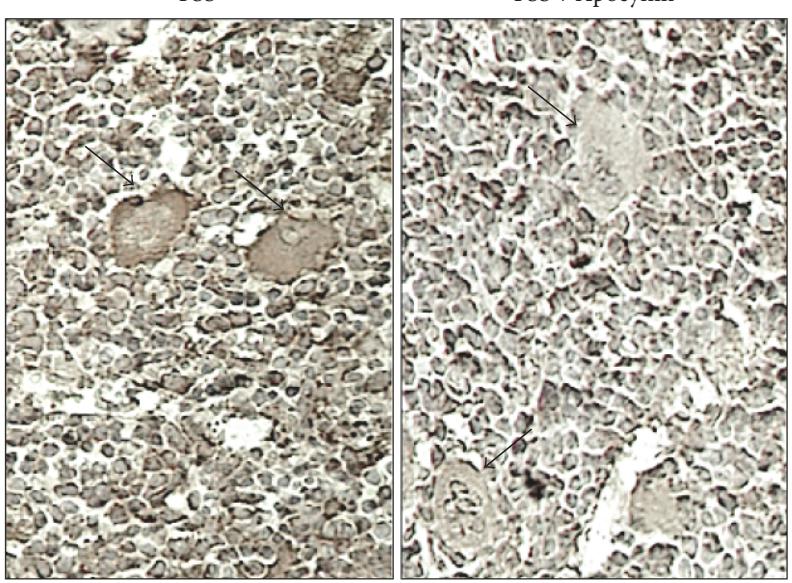

(b)

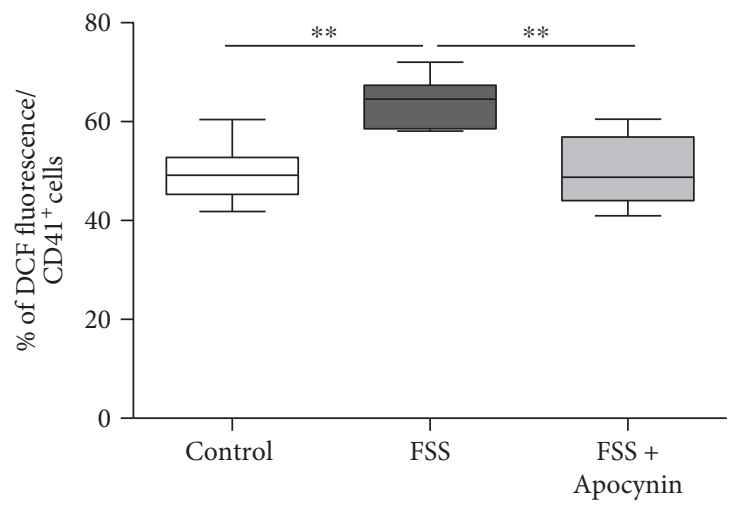

(c)

FIGURE 7: Apocynin prevents oxidative stress in megakaryocytes of stressed mice. Control mice and mice exposed to forced swimming stress (FSS) were treated with vehicle or with Apocynin (FSS + Apocynin), and then (a) NADPH/NADP ${ }^{+}$ratio was measured in bone marrow. (b) Immunoperoxidase staining of NOX1 was performed in bone marrow. (c) Reactive oxygen species (ROS) levels were detected by H2DCFDA in MKs, as described in Methods. $n=6$ mice/group. ${ }^{* *} p<0.01$ and ${ }^{* * * *} p<0.001$. For each box-plot, the center line illustrates the median and box limits indicate the 25th and 75th percentiles. Data were analyzed by the Kruskal-Willis test followed by a Dunn's multiple comparison test.

session, performed twice a day for 4 consecutive days, is sufficient to induce a greater and more stable clot and to predispose mice to arterial thrombosis, without affecting fibrinogen and coagulation factor activation in agreement with data obtained by other stress models, such as restraint or foot shock stress [40,43]. In addition, stressed mice not only have a higher number of circulating cells (leukocytes and platelets) but also have bigger, reticulated, and hyperresponsive platelets as previously reported in human studies $[35,44-46]$, which suggest modification in bone marrow milieu. Indeed, thrombopoiesis is a complex process resulting from many consecutive steps including proliferation and maturation of megakaryocytes [47]. Accordingly, we provide evidence that chronic stress increases the number 
of bone marrow megakaryocytes and it affects morphology as well. Megakaryocytes from stressed mice display an advanced maturation state, in terms of bigger size, greater nuclear complexity, and enhanced expression of CD42d antigen. In addition, megakaryocytes from stressed mice produce higher levels of ROS.

Previous studies have shown that both sympathetic transmitters (e.g., norepinephrine and epinephrine) and ROS promote proliferation of hematopoietic stem cells, their differentiation to megakaryocytes, and they induce megakaryocyte adhesion, migration, and proplatelet formation [33, 48]. Intriguingly, chronic stress increases norepinephrine levels in bone marrow [35], which in turn increases NADPH oxidase-derived superoxide in different type of cells $[49,50]$, suggesting a potential link between these cellular messengers under chronic stress condition. Moreover, we show that the NOX1 catalytic subunit, expressed in different type of cells, including macrophages, hematopoietic stem cells, and megakaryocytes $[36,51,52]$, is upregulated by chronic stress in all bone marrow cells and not only in megakaryocytes.

Interestingly, previous experiments performed with different oxidase inhibitors suggest that the NADPH oxidase enzyme is the critical source of ROS in megakaryocytes [53] and that NADPH oxidase inhibition completely prevents the signaling cascade activation required for megakaryocyte differentiations [54], reducing their polyploidization [36]. However, the single deletion of NOX1 or of NOX2 alone, some of the subunits of NADPH oxidase, is not sufficient to modulate MK polyploidization [36] as provided by in vivo experiment, supporting the concept of a mutual compensation between the NOX isoforms.

Experimental and clinical data show that NADPH oxidase plays a key role also in platelet ROS generation and platelet activation [7, 55-57].

In line with these findings, we show here for the first time that Apocynin treatment prevents the detrimental effect of chronic psychological/behavioral stress, affecting production of ROS and leading to thrombosis, throughout the regulation of megakaryopoiesis and platelet activation.

In particular, the strong effect of Apocynin in the prevention of prothrombotic phenotype promoted by environmental stress may be the result of a pleiotropic effect of this compound on different cells and tissues (e.g., megakaryocytes, bone marrow milieu, platelets, and vessel walls). Indeed, the higher levels of NOX1 expression induced by chronic stress in bone marrow cells, including also megakaryocytes, are significantly reduced by Apocynin treatment. In addition, Apocynin prevents platelet activation and improves endothelial/vascular function [58, 59] reducing ROS by preventing their generation by the binding of NOXO1 and p47phox to p22phox and/or decreasing Rho kinases activity [60] and acting as radical scavenger [18]. However, Apocynin may affect platelet function also by a mechanism different from the abovementioned, which has not been well identified [61]. In particular, it is demonstrated that Apocynin might indirectly inhibit NADPH oxidase activity depleting its catalytic substrates such as NADPH [62] and decreasing the intracellular reduce/oxidase GSH/GSSG ratio [63].

\section{Conclusion}

Our data not only provide new important knowledge about the mechanisms by which chronic stress affects arterial thrombosis but also suggest that Apocynin is useful in the prevention of thrombosis associated to chronic environmental stress.

\section{Disclosure}

A part of this manuscript had been presented as a meeting abstract (Arteriosclerosis, Thrombosis, and Vascular Biology. 2017; 37: A29).

\section{Conflicts of Interest}

The authors declare that they have no conflicts of interest.

\section{Acknowledgments}

The authors would like to thank Dr. Elisa Turra for the technical immunohistochemistry support. The present work was supported by the Italian Ministry of Health (Ricerca Corrente: BIO33-2013, ID: 2600692; BIO33-2014, ID: 2607452; BIO33-2015, ID: 2622789; BIO37-2016, ID: 2613074; BIO37-2017, ID: 2631213). Cofunding was provided by the contribution of the Italian " $5 \times 1000$ ” tax (2013 and 2014).

\section{References}

[1] D. S. Krantz, D. S. Sheps, R. M. Carney, and B. H. Natelson, "Effects of mental stress in patients with coronary artery disease: evidence and clinical implications," JAMA, vol. 283, no. 14, pp. 1800-1802, 2000.

[2] M. A. Mittleman, M. Maclure, J. B. Sherwood et al., "Triggering of acute myocardial infarction onset by episodes of anger. Determinants of myocardial infarction onset study investigators," Circulation, vol. 92, no. 7, pp. 1720-1725, 1995.

[3] A. Steptoe and M. Kivimaki, "Stress and cardiovascular disease," Nature Reviews. Cardiology, vol. 9, no. 6, pp. 360370, 2012.

[4] R. von Kanel, P. J. Mills, C. Fainman, and J. E. Dimsdale, "Effects of psychological stress and psychiatric disorders on blood coagulation and fibrinolysis: a biobehavioral pathway to coronary artery disease?," Psychosomatic Medicine, vol. 63, no. 4, pp. 531-544, 2001.

[5] J. A. Leopold and J. Loscalzo, "Oxidative risk for atherothrombotic cardiovascular disease," Free Radical Biology \& Medicine, vol. 47, no. 12, pp. 1673-1706, 2009.

[6] D. Pietraforte, R. Vona, A. Marchesi et al., "Redox control of platelet functions in physiology and pathophysiology," Antioxidants \& Redox Signaling, vol. 21, no. 1, pp. 177193, 2014.

[7] A. J. Begonja, S. Gambaryan, J. Geiger et al., "Platelet $\mathrm{NAD}(\mathrm{P}) \mathrm{H}$-oxidase-generated ROS production regulates $\alpha \mathrm{IIb} \beta 3$-integrin activation independent of the NO/cGMP pathway," Blood, vol. 106, no. 8, pp. 2757-2760, 2005.

[8] J. S. Seo, J. Y. Park, J. Choi et al., "NADPH oxidase mediates depressive behavior induced by chronic stress in mice," The Journal of Neuroscience, vol. 32, no. 28, pp. 9690-9699, 2012. 
[9] P. Wenzel, S. Kossmann, T. Munzel, and A. Daiber, "Redox regulation of cardiovascular inflammation - immunomodulatory function of mitochondrial and Nox-derived reactive oxygen and nitrogen species," Free Radical Biology \& Medicine, vol. 109, pp. 48-60, 2017.

[10] F. Jiang, Y. Zhang, and G. J. Dusting, "NADPH oxidasemediated redox signaling: roles in cellular stress response, stress tolerance, and tissue repair," Pharmacological Reviews, vol. 63, no. 1, pp. 218-242, 2011.

[11] F. Violi and P. Pignatelli, "Platelet oxidative stress and thrombosis," Thrombosis Research, vol. 129, no. 3, pp. 378-381, 2012.

[12] N. Panth, K. R. Paudel, and K. Parajuli, "Reactive oxygen species: a key Hallmark of cardiovascular disease," Advances in Medicine, vol. 2016, Article ID 9152732, 12 pages, 2016.

[13] M. Patel, "Targeting oxidative stress in central nervous system disorders," Trends in Pharmacological Sciences, vol. 37, no. 9, pp. 768-778, 2016.

[14] S. Schiavone and L. Trabace, "Pharmacological targeting of redox regulation systems as new therapeutic approach for psychiatric disorders: a literature overview," Pharmacological Research, vol. 107, pp. 195-204, 2016.

[15] S. Heumuller, S. Wind, E. Barbosa-Sicard et al., "Apocynin is not an inhibitor of vascular NADPH oxidases but an antioxidant," Hypertension, vol. 51, no. 2, pp. 211-217, 2008.

[16] F. Engels, B. F. Renirie, B. A. Hart, R. P. Labadie, and F. P. Nijkamp, "Effects of apocynin, a drug isolated from the roots of Picrorhiza kurroa, on arachidonic acid metabolism," FEBS Letters, vol. 305, no. 3, pp. 254-256, 1992.

[17] J. M. Simons, L. A. Hart, H. van Dijk, F. C. Fischer, K. T. de Silva, and R. P. Labadie, "Immunodulatory compounds from Picrorhiza kurroa: isolation and characterization of two anti-complementary polymeric fractions from an aqueous root extract," Journal of Ethnopharmacology, vol. 26, no. 2, pp. 169-182, 1989.

[18] M. S. Petronio, M. L. Zeraik, L. M. Fonseca, and V. F. Ximenes, "Apocynin: chemical and biophysical properties of a NADPH oxidase inhibitor," Molecules, vol. 18, no. 3, pp. 2821-2839, 2013.

[19] K. A. Trumbull, D. McAllister, M. M. Gandelman et al., "Diapocynin and apocynin administration fails to significantly extend survival in G93A SOD1 ALS mice," Neurobiology of Disease, vol. 45, no. 1, pp. 137-144, 2012.

[20] M. Dumont, C. Stack, C. Elipenhali, N. Y. Calingasan, E. Wille, and M. F. Beal, "Apocynin administration does not improve behavioral and neuropathological deficits in a transgenic mouse model of Alzheimer's disease," Neuroscience Letters, vol. 492, no. 3, pp. 150-154, 2011.

[21] E. A. Stone, M. L. Lehmann, Y. Lin, and D. Quartermain, "Reduced evoked fos expression in activity-related brain regions in animal models of behavioral depression," Progress in Neuro-Psychopharmacology and Biological Psychiatry, vol. 31, no. 6, pp. 1196-1207, 2007.

[22] E. A. Stone and Y. Lin, "Open-space forced swim model of depression for mice," Current Protocols in Neuroscience, Chapter 9, p. 36, 2011.

[23] E. A. Stone, Y. Lin, and D. Quartermain, "Evaluation of the repeated open-space swim model of depression in the mouse," Pharmacology, Biochemistry, and Behavior, vol. 91, no. 1, pp. 190-195, 2008.

[24] E. Meshorer, B. Bryk, D. Toiber et al., "SC35 promotes sustainable stress-induced alternative splicing of neuronal acetylcholinesterase mRNA," Molecular Psychiatry, vol. 10, no. 11, pp. 985-997, 2005.

[25] B. S. Sailaja, D. Cohen-Carmon, G. Zimmerman, H. Soreq, and E. Meshorer, "Stress-induced epigenetic transcriptional memory of acetylcholinesterase by HDAC4," Proceedings of the National Academy of Sciences of the United States of America, vol. 109, no. 52, pp. E3687-E3695, 2012.

[26] T. Serchov, H. W. Clement, M. K. Schwarz et al., "Increased signaling via adenosine $A_{1}$ receptors, sleep deprivation, imipramine, and ketamine inhibit depressive-like behavior via induction of Homerla," Neuron, vol. 87, no. 3, pp. 549-562, 2015.

[27] P. Amadio, G. I. Colombo, E. Tarantino et al., "BDNFVal66met polymorphism: a potential bridge between depression and thrombosis," European Heart Journal, vol. 38, no. 18, pp. 1426-1435, 2017.

[28] F. Bonacina, S. S. Barbieri, L. Cutuli et al., "Vascular pentraxin 3 controls arterial thrombosis by targeting collagen and fibrinogen induced platelets aggregation," Biochimica et Biophysica Acta (BBA) - Molecular Basis of Disease, vol. 1862, no. 6, pp. 1182-1190, 2016.

[29] P. Amadio, E. Tarantino, L. Sandrini, E. Tremoli, and S. S. Barbieri, "Prostaglandin-endoperoxide synthase-2 deletion affects the natural trafficking of Annexin A2 in monocytes and favours venous thrombosis in mice," Thrombosis and Haemostasis, vol. 117, no. 8, pp. 1486-1497, 2017.

[30] S. S. Barbieri, G. Petrucci, E. Tarantino et al., "Abnormal megakaryopoiesis and platelet function in cyclooxygenase-2deficient mice," Thrombosis and Haemostasis, vol. 114, no. 6, pp. 1218-1229, 2015.

[31] S. S. Barbieri, P. Amadio, S. Gianellini, E. Zacchi, B. B. Weksler, and E. Tremoli, "Tobacco smoke regulates the expression and activity of microsomal prostaglandin E synthase-1: role of prostacyclin and NADPH-oxidase," The FASEB Journal, vol. 25, no. 10, pp. 3731-3740, 2011.

[32] M. Trakala, D. Partida, M. Salazar-Roa et al., "Activation of the endomitotic spindle assembly checkpoint and thrombocytopenia in Plk1-deficient mice," Blood, vol. 126, no. 14, pp. 1707$1714,2015$.

[33] S. Chen, C. Du, M. Shen et al., "Sympathetic stimulation facilitates thrombopoiesis by promoting megakaryocyte adhesion, migration, and proplatelet formation," Blood, vol. 127, no. 8, pp. 1024-1035, 2016.

[34] C. Giannarelli, D. T. Rodriguez, M. U. Zafar et al., "Susceptibility to chronic social stress increases plaque progression, vulnerability and platelet activation," Thrombosis and Haemostasis, vol. 117, no. 4, pp. 816-818, 2017.

[35] T. Heidt, H. B. Sager, G. Courties et al., "Chronic variable stress activates hematopoietic stem cells," Nature Medicine, vol. 20, no. 7, pp. 754-758, 2014.

[36] D. J. McCrann, A. Eliades, M. Makitalo, K. Matsuno, and K. Ravid, "Differential expression of NADPH oxidases in megakaryocytes and their role in polyploidy," Blood, vol. 114, no. 6, pp. 1243-1249, 2009.

[37] B. S. McEwen, "Physiology and neurobiology of stress and adaptation: central role of the brain," Physiological Reviews, vol. 87, no. 3, pp. 873-904, 2007.

[38] A. W. Goddard, S. G. Ball, J. Martinez et al., "Current perspectives of the roles of the central norepinephrine system in anxiety and depression," Depression and Anxiety, vol. 27, no. 4, pp. 339-350, 2010. 
[39] A. Rosengren, S. Hawken, S. Ounpuu et al., "Association of psychosocial risk factors with risk of acute myocardial infarction in 11119 cases and 13648 controls from 52 countries (the INTERHEART study): case-control study," Lancet, vol. 364, no. 9438, pp. 953-962, 2004.

[40] S. F. Stampfli, G. G. Camici, S. Keller et al., "Restraint stress enhances arterial thrombosis in vivo - role of the sympathetic nervous system," Stress, vol. 17, no. 1, pp. 126-132, 2014.

[41] Y. Uchida, K. Takeshita, K. Yamamoto et al., "Stress augments insulin resistance and prothrombotic state: role of visceral adipose-derived monocyte chemoattractant protein-1," Diabetes, vol. 61, no. 6, pp. 1552-1561, 2012.

[42] K. Yamamoto, T. Shimokawa, H. Yi et al., "Aging and obesity augment the stress-induced expression of tissue factor gene in the mouse," Blood, vol. 100, no. 12, pp. 4011-4018, 2002.

[43] T. Dong, Y. W. Cheng, F. Yang et al., "Chronic stress facilitates the development of deep venous thrombosis," Oxidative Medicine and Cellular Longevity, vol. 2015, Article ID 384535, 8 pages, 2015.

[44] P. Hjemdahl, P. T. Larsson, and N. H. Wallen, "Effects of stress and beta-blockade on platelet function," Circulation, vol. 84, 6 Supplement, pp. VI44-VI61, 1991.

[45] P. T. Larsson, P. Hjemdahl, G. Olsson, N. Egberg, and G. Hornstra, "Altered platelet function during mental stress and adrenaline infusion in humans: evidence for an increased aggregability in vivo as measured by filtragometry," Clinical Science, vol. 76, no. 4, pp. 369-376, 1989.

[46] S. M. Patterson, D. S. Krantz, J. S. Gottdiener, G. Hecht, S. Vargot, and D. S. Goldstein, "Prothrombotic effects of environmental stress: changes in platelet function, hematocrit, and total plasma protein," Psychosomatic Medicine, vol. 57, no. 6, pp. 592-599, 1995.

[47] J. C. Kostyak, M. U. Naik, and U. P. Naik, "Calcium- and integrin-binding protein 1 regulates megakaryocyte ploidy, adhesion, and migration," Blood, vol. 119, no. 3, pp. 838-846, 2012.

[48] Y. F. Wang, C. H. Tsai, Y. T. Huang et al., "Size distribution of airborne fungi in vehicles under various driving conditions," Archives of Environmental \& Occupational Health, vol. 68, no. 2, pp. 95-100, 2013.

[49] S. H. Deo, N. T. Jenkins, J. Padilla, A. R. Parrish, and P. J. Fadel, "Norepinephrine increases NADPH oxidase-derived superoxide in human peripheral blood mononuclear cells via $\alpha$-adrenergic receptors," American Journal of PhysiologyRegulatory, Integrative and Comparative Physiology, vol. 305, no. 10, pp. R1124-R1132, 2013.

[50] F. Xiong, D. Xiao, and L. Zhang, "Norepinephrine causes epigenetic repression of $\mathrm{PKC} \varepsilon$ gene in rodent hearts by activating Nox1-dependent reactive oxygen species production," The FASEB Journal, vol. 26, no. 7, pp. 2753-2763, 2012.

[51] M. Gimenez, B. M. Schickling, L. R. Lopes, and F. J. Miller Jr., "Nox1 in cardiovascular diseases: regulation and pathophysiology," Clinical Science, vol. 130, no. 3, pp. 151-165, 2016.

[52] C. Piccoli, A. D'Aprile, M. Ripoli et al., "Bone-marrow derived hematopoietic stem/progenitor cells express multiple isoforms of NADPH oxidase and produce constitutively reactive oxygen species," Biochemical and Biophysical Research Communications, vol. 353, no. 4, pp. 965-972, 2007.

[53] C. Prata, T. Maraldi, L. Zambonin, D. Fiorentini, G. Hakim, and L. Landi, "ROS production and Glut1 activity in two human megakaryocytic cell lines," BioFactors, vol. 20, no. 4, pp. 237-247, 2004.

[54] J. L. Sardina, G. Lopez-Ruano, L. I. Sanchez-Abarca et al., "p22 $2^{\text {phox }}$-dependent NADPH oxidase activity is required for megakaryocytic differentiation," Cell Death and Differentiation, vol. 17, no. 12, pp. 1842-1854, 2010.

[55] R. Carnevale, L. Loffredo, C. Nocella et al., "Impaired platelet activation in patients with hereditary deficiency of $\mathrm{p} 47^{\text {phox }}$," British Journal of Haematology, 2016.

[56] S. Chlopicki, R. Olszanecki, M. Janiszewski, F. R. M. Laurindo, T. Panz, and J. Miedzobrodzki, "Functional role of NADPH oxidase in activation of platelets," Antioxidants \& Redox Signaling, vol. 6, no. 4, pp. 691-698, 2004.

[57] K. Y. Stokes, J. M. Russell, M. H. Jennings, J. S. Alexander, and D. N. Granger, "Platelet-associated NAD $(\mathrm{P}) \mathrm{H}$ oxidase contributes to the thrombogenic phenotype induced by hypercholesterolemia," Free Radical Biology \& Medicine, vol. 43, no. 1, pp. 22-30, 2007.

[58] D. Pastori, P. Pignatelli, R. Carnevale, and F. Violi, "Nox-2 upregulation and platelet activation: novel insights," Prostaglandins \& Other Lipid Mediators, vol. 120, pp. 50-55, 2015.

[59] A. Virdis, M. Gesi, and S. Taddei, "Impact of apocynin on vascular disease in hypertension," Vascular Pharmacology, vol. 87, pp. 1-5, 2016.

[60] T. Maraldi, "Natural compounds as modulators of NADPH oxidases," Oxidative Medicine and Cellular Longevity, vol. 2013, Article ID 271602, 10 pages, 2013.

[61] J. Dharmarajah, J. F. Arthur, C. G. Sobey, and G. R. Drummond, "The anti-platelet effects of apocynin in mice are not mediated by inhibition of NADPH oxidase activity," Naunyn-Schmiedeberg's Archives of Pharmacology, vol. 382, no. 4, pp. 377-384, 2010.

[62] G. Galati, O. Sabzevari, J. X. Wilson, and P. J. O'Brien, "Prooxidant activity and cellular effects of the phenoxyl radicals of dietary flavonoids and other polyphenolics," Toxicology, vol. 177, no. 1, pp. 91-104, 2002.

[63] S. S. Barbieri, V. Cavalca, S. Eligini et al., "Apocynin prevents cyclooxygenase 2 expression in human monocytes through NADPH oxidase and glutathione redox-dependent mechanisms," Free Radical Biology \& Medicine, vol. 37, no. 2, pp. 156-165, 2004. 


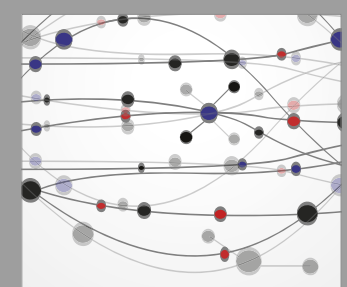

The Scientific World Journal
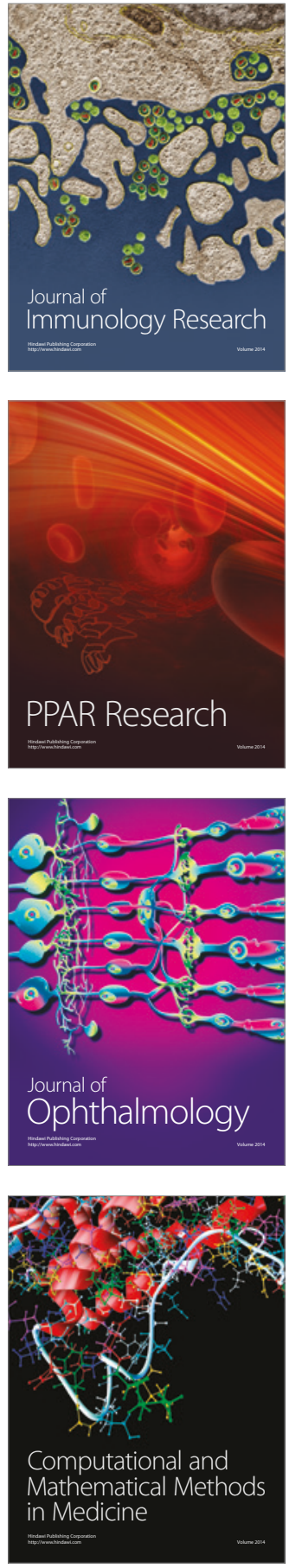

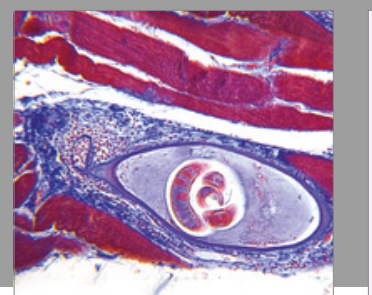

Gastroenterology Research and Practice
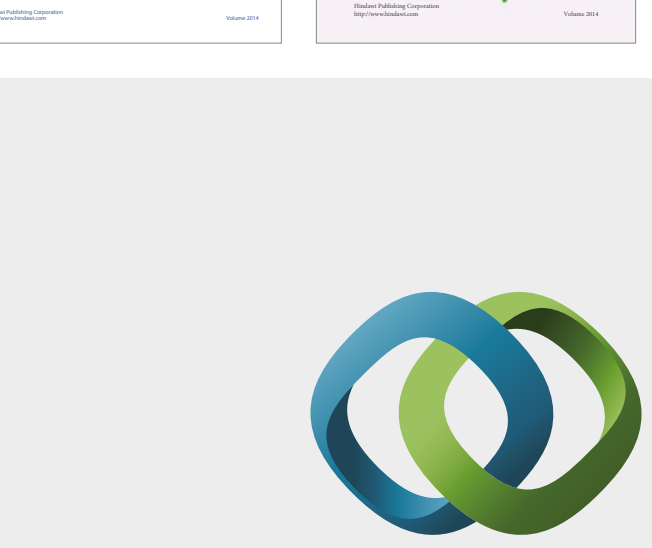

\section{Hindawi}

Submit your manuscripts at

https://www.hindawi.com
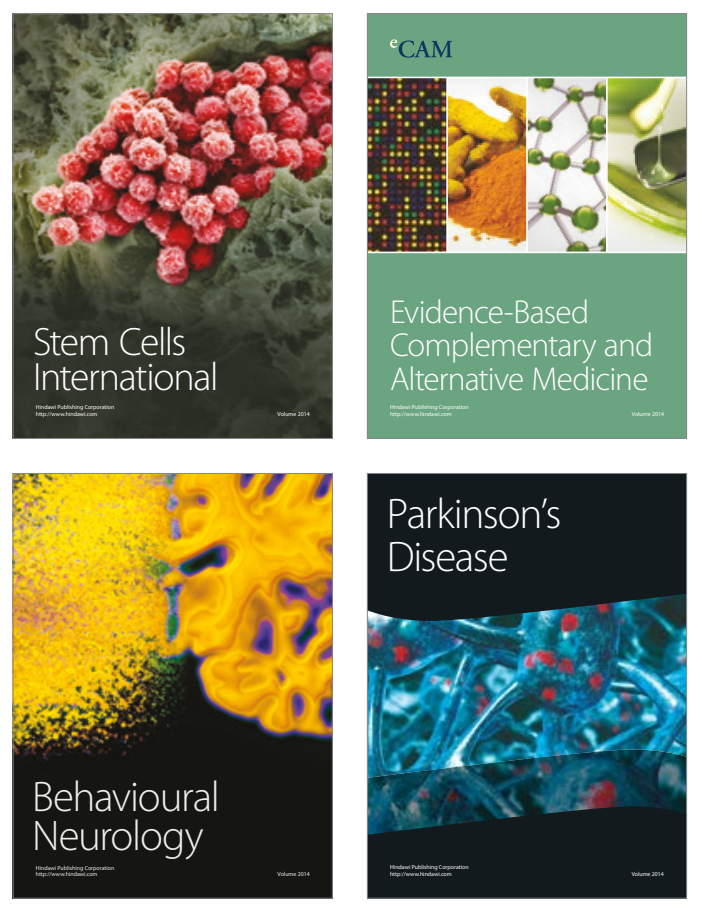
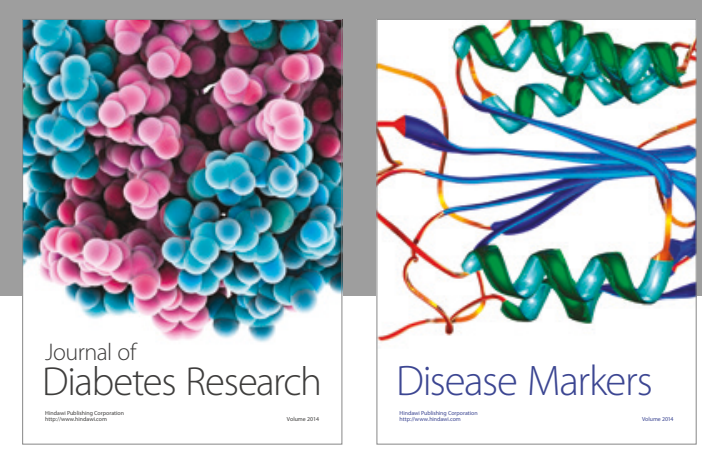

Disease Markers
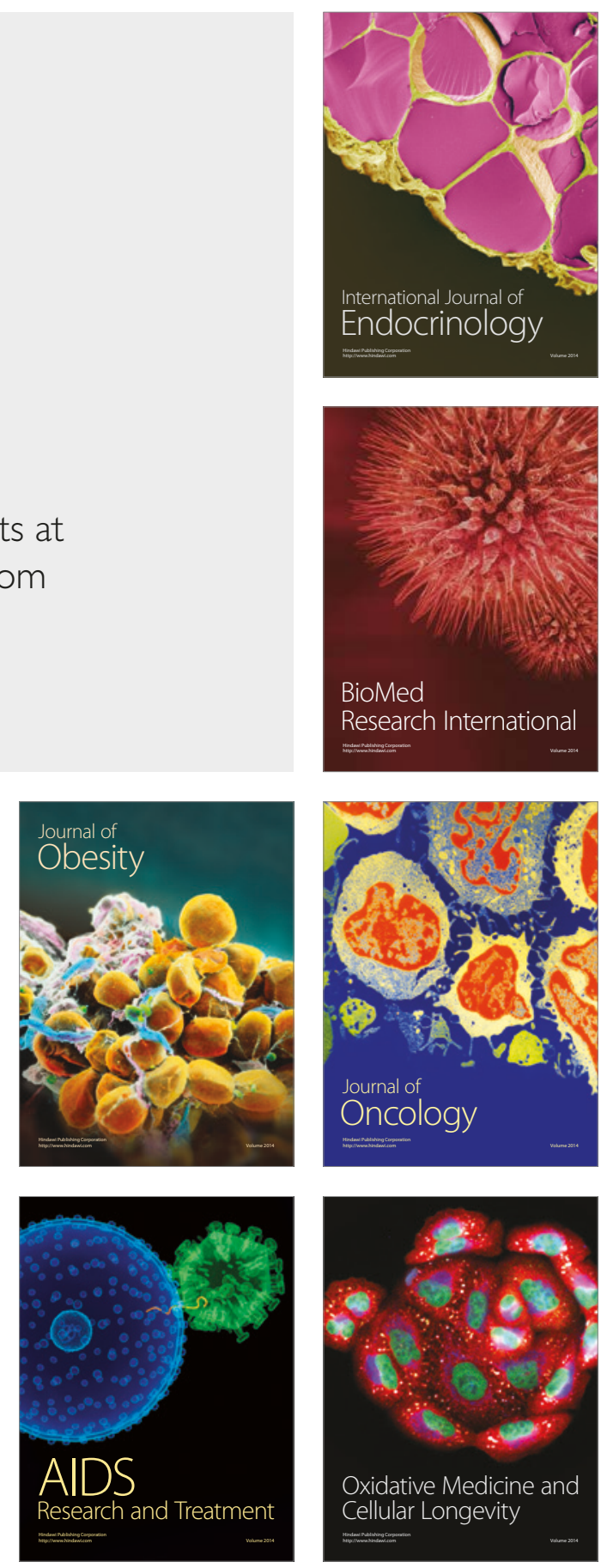